\title{
CAPITAL PRÓPRIO, CAPITAL DE TERCEIROS OU AMBOS EXERCEM INFLUÊNCIA NOS PILARES DA RESPONSABILIDADE SOCIAL CORPORATIVA?
}

\author{
Paula Pontes de Campos-Rasera \\ Universidade Federal do Paraná \\ Gabriela de Abreu Passos \\ Universidade Federal do Paraná \\ Romualdo Douglas Colauto \\ Universidade Federal do Paraná
}

\begin{abstract}
RESUMO
Pressões externas e internas exercem influência na reputação corporativa com reflexos na Responsabilidade Social Corporativa (RSC) e na estrutura de capital. Diante disso, este estudo investiga a influência do capital próprio e o de terceiros nos pilares da RSC. A literatura aponta que as empresas sofrem pressões de agentes externos para que adotem comportamentos ambientais, sociais e de governança. Parte dessas pressões se materializa na estrutura de capital das empresas e a sua separação em capital próprio e de terceiros representa, nesta pesquisa, as pressões exercidas pelos acionistas e demais stakeholders respectivamente. Assim, desenvolvese seis hipóteses para verificar as relações entre o capital próprio e de terceiros com os três pilares da RSC. Para tanto, utiliza-se uma amostra composta por 1.679 companhias de capital aberto nas bolsas dos dez países com maiores PIBs, no período de 2001 a 2018. Os achados indicam divergências entre o capital próprio e o de terceiros em cada pilar da RSC e ainda, diferenças em cada país e setor de atuação das empresas. De modo particular, nota-se a relevância do pilar Social, o qual para atingir determinado grau em seu índice de desempenho necessita de menor aporte da fonte de financiamento do capital próprio que os índices ambiental e de governança. Dessa forma, busca-se contribuir com a literatura ao verificar qual grupo da estrutura de capital os stakeholders exercem mais pressões sobre cada dimensão da RSC, fomentando discussões acerca dos motivos que levam as organizações a adotarem práticas socialmente responsáveis.
\end{abstract}

Palavras-chave: Estrutura de Capital; Capital Próprio; Capital de Terceiros; Pilares da Responsabilidade Social Corporativa.

\section{INTRODUÇÃ̃}

Avanços tecnológicos e na comunicação colocaram em exposição a reputação corporativa às críticas e pressões dos stakeholders, com poder de alcance em audiência global e mobilização de protestos em nível multinacional. O The Global Risks Report, em sua $15^{\circ}$ edição, definiu os principais temas discutidos no World Economic Forum 2020 e fatores que afetam o risco global. Entre os cinco primeiros estão: clima extremo, falhas nas ações climáticas, desastres naturais, ameaças à biodiversidade e desastres ambientais causados pelo homem. Adicionalmente, o 23 Annual Global CEO Survey realizado pela PWC constatou que entre as dez preocupações que os CEOs possuem e que podem ameaçar a perspectiva de crescimento das companhias estão: as mudanças climáticas e os danos ambientais. O conjunto desses resultados indica a crescente preocupação atribuída pelas organizações às questões de sociais e ambientais, a qual tem se transformado em práticas sociais responsáveis.

A disseminação da Responsabilidade Social Corporativa (RSC), tanto nos países a nível das organizações como na academia, sinaliza uma mudança de pensamento na qual as forças 
políticas e da comunidade buscam o equilíbrio da sustentabilidade entre o econômico, o social e o ambiental (Campbell, 2007; Chen, Hung \& Wang, 2018). O foco das ações empresariais passa a não ser apenas os direitos dos acionistas, mas sim a maximização dos interesses de todas as partes interessadas (Al-Dah, Dah \& Jazi, 2018; Baraibar-Diez \& Sotorrío, 2018; Yang et al., 2018; Haninun et al., 2019).

A adoção das práticas de RSC pelas organizações resulta das pressões internas e externas para que assumam o compromisso de serem socialmente responsáveis (Al-Dah et al., 2018). Os achados de Chen et al. (2018) apontam que os investimentos relacionados a RSC são em grande parte impulsionados por forças políticas e sociais e que, não necessariamente, as empresas obterão retornos financeiros com tais práticas.

Apesar das empresas nem sempre alcançarem resultados financeiros positivos, a RSC gera para entidade outros tipos de resultado, principalmente, os intangíveis. Sobre isso, Saeidi et al. (2015) relatam que a RSC auxilia na produção de legitimidade, confiabilidade, vantagens competitivas e, sobretudo, de reputação. De acordo com Chakraborty, Gao e Sheikh (2019), a RSC contribui para o aumento da reputação corporativa por funcionar como sinalização da manutenção dos compromissos assumidos, conduzindo uma melhora do relacionamento entre a empresa e seus stakeholders.

É perceptível a relevância dos stakeholders para as companhias, pois esses validam as ações de RSC. Porém, a validação ocorrerá somente quando tais práticas atenderem suas expectativas sobre o quê seria apropriado e aceitável. Diante desse fato, os gestores ponderam as pressões recebidas pela empresa para a implementação de práticas sociais responsáveis (McWilliams, Siegel \& Wright, 2006; Hamrouni, Boussaada \& Toumi, 2019).

Pesquisadores defendem que a RSC possui, antes de tudo, relação com a estrutura de capital das empresas, uma vez que esse arranjo representa a materialização da influência dos stakeholders sobre as organizações (Almeida \& Santos, 2016; Yang et al., 2018; Bae et al., 2019; Hamrouni et al., 2019). Essa influência decorre do financiamento das atividades operacionais devido a contração de dívidas com os seus stakeholders. Assim, o envolvimento com ações socialmente responsáveis gera impactos no acesso ao financiamento pelas organizações, seja através do capital próprio ou de terceiros (Almeida \& Santos, 2016; Yang et al., 2018; Hamrouni, et al., 2019).

Tanto a estrutura de capital quanto a RSC diferenciam-se em sua composição. Em outras palavras, a estrutura de capital identifica-se pela origem de suas fontes de financiamento, de terceiros ou próprio, ao passo que, a RSC constitui-se pelas dimensões social, ambiental e de governança. Em cada uma dessas dimensões, ou seja, pilares, são utilizadas distintas ferramentas para implementação e manutenção de tais práticas. Assim, a relevância do estudo da RSC atribui-se à investigação desses pilares, uma vez que cada elemento interfere de modo diferente nas percepções dos stakeholders (Dahlsrud, 2008; Hamrouni et al., 2019).

Diante do exposto, a pesquisa possui o objetivo de investigar os efeitos do capital próprio e de terceiros nos pilares da responsabilidade social corporativa. Para tanto, utiliza-se uma amostra composta por empresas de capital aberto listadas em bolsas nas dez maiores economias do mundo. Isso porque, as demandas de RSC podem variar dependendo do país, do setor atuação e das características econômicas na qual as companhias estão inseridas (McWilliams et al., 2006; Garcia, Mendes-da-Silva \& Orsato, 2019).

Assumindo o prisma que as companhias sofrem pressões internas e externas, uma importante contribuição da pesquisa é identificar em qual grupo da estrutura de capital os stakeholders exercem mais pressões sobre os pilares da RSC, averiguando também as diferenças existentes entre as dez maiores economias do mundo. Além disso, o estudo propicia discussões sobre os motivos que levam as organizações a adotarem ações de RSC dado a visualização de práticas sociais responsáveis analisadas de forma fragmentada. 


\section{REVISÃO DA LITERATURA E DESENVOLVIMENTO DAS HIPÓTESES}

Apesar de não existir consenso na literatura, a RSC pode ser entendida como o compromisso contraído pelas companhias, a qual envolve questões sociais, ambientais e de gestão (Gössling \& Vocht, 2007). Conforme apontado por Carroll (1979), a RSC se traduz no compromisso da empresa com a sociedade, abrangendo expectativas econômicas, legais, éticas e filantrópicas que a comunidade espera da organização. Apesar disso, a definição do termo não se mantém fixa no tempo, visto que ela é produto de discussões históricas sobre o impacto das organizações na sociedade (Campbell, 2007; Carroll, 2008; Kraus \& Brtitzelmaier, 2012).

As pesquisas costumam retratar a RSC em três pilares: o ambiental, o social e o de governança. De acordo com Dahlsrud (2008), essas dimensões representam conjuntos de diferentes impactos nas companhias e revelam que as empresas não geram apenas impactos econômicos, mas também, produzem riquezas econômicas. Sidhoum e Serra (2018) mostram que os elementos que compõem a RSC estão interconectados e que as organizações estão integrando sistemas sociais, ambientais e de governança nas suas práticas de negócio.

Essas adoções no comportamento organizacional podem ser entendidas como pressões externas e internas que as companhias sofrem de seus stakeholders, o que inclui os acionistas, Governo, funcionários, bancos, entre outros (Campbell, 2007; Al-Dah et al., 2018). Segundo Cosenza et al. (2018), as empresas buscam a legitimidade de suas ações frente aos seus stakeholders como resposta às pressões externas. Essa legitimidade das práticas de RSC é originada, principalmente, dos atores externos que podem aumentar as percepções positivas da empresa e a reputação corporativa, consequentemente, trazendo retornos para as firmas (PradoLorenzo, Gallego-Alvarez \& Garcia-Sanchez, 2009; Baraibar-Diez \& Sotorrío, 2018; Xiao et al., 2018; Hamrouni et al., 2019).

Diferentes pesquisas têm encontrado evidências sobre as consequências da RSC nas companhias; Teixeira, Nossa e Funchal (2011) encontraram relação negativa entre as divulgações de RSC e o risco da firma. Servaes e Tamayo (2013) verificaram que as ações sociais responsáveis aumentam o valor da empresa; Cho, Lee e Pfeiffer Jr. (2013) averiguaram redução da assimetria informacional nas companhias com alta RSC; Baraibar-Diez e Sotorrío (2018) e Chakraborty et al. (2019) constataram aumento da reputação corporativa frente as divulgações de RSC.

Com efeito, McWilliams et al. (2006) argumentam que a alta administração tem ciência das pressões que a organização recebe para a adoção de RSC e dos efeitos que essa pode gerar. Hamrouni et al. (2019) ressaltam que são essas consequências que levam a ponderação pelos gestores sobre a implementação da RSC nas companhias. Para Almeida e Santos (2016), Yang et al. (2018) e Bae et al. (2019) o emprego de práticas de RSC é considerado pelas empresas de acordo com a composição da estrutura de capital.

Com relação ao capital próprio, Eding e Scholtens (2017) discorrem que esse grupo de interessados cada vez mais se envolvem em investimentos que demonstrem serem sociais responsáveis e que tal engajamento exerce pressões nas organizações para essas assumirem práticas ambientais, sociais e de governança. Isso porque, a RSC agregaria valor à empresa, por demonstrar o compromisso assumido com todos os stakeholders e melhorar o relacionamento entre as partes internas e externas da organização, o que incentivaria o acionista a manter ou aumentar o seu capital na entidade, e ainda, ajudaria a atrair novos investidores.

Em relação ao capital de terceiros, a RSC conduz à tendência das empresas contraírem dívidas visto a maior disponibilidade de crédito, pois essas práticas reduzem a assimetria informacional e ocasionam menor tendência de existir risco litigiosos que podem fazer com que as firmas não liquidem as dívidas contraídas (Almeida \& Santos, 2016; Cheng, Ioannou \& Serafeim, 2014; Chen et al., 2018). Essa facilidade de acesso, em parte, também deriva da reputação regrada pela RSC, a qual aumentaria a confiança entre a empresa e os seus credores 
e assim, como recompensa para altos níveis de RSC haveria essa facilitação do acesso à tomada de dívidas (Hamrouni et al., 2019).

Ademais, Hamrouni et al. (2019) colocam que além dos impactos da estrutura de capital na RSC, as análises que a envolvem precisam considerar as três dimensões que compõem as práticas socialmente responsáveis, uma vez que as expectativas de cada pilar - ambiental, social e governança - podem diferir de stakeholder para stakeholder. Bae et al. (2019) esclarecem que o olhar decomposto sobre a RSC possibilita visualizar melhor as influências em cada pilar.

O pilar Ambiental recebe menor interesse dos pesquisadores, todavia possui a mesma relevância que os demais. Apesar disso, o envolvimento com práticas ambientais é resultado das pressões sociais e políticas que as corporações enfrentam para que assumam o compromisso de contribuir com um meio ambiente mais limpo e a sua preservação (Clarkson et al., 2008; Kanji \& Chopra, 2010). Em casos de riscos ambientais mais altos, as partes interessadas possuem preocupações mais altas em relação à sustentabilidade corporativa e, assim, as empresas devem prestar atenção nessas práticas para obter legitimidade (Haninun et al., 2019).

Cai, Jo e Pan (2012) verificaram que as indústrias poluentes enfrentam maiores pressões para se envolverem em atividades de RSC. Do mesmo modo, Almeida e Santos (2016) constataram que as empresas mais poluidoras possuem maiores divulgações de RSC como forma de demonstrar ao mercado a reparação ambiental do dano gerado pela companhia e assim, não sofrerem retaliações. Já Haninun et al. (2019) encontraram uma relação negativa entre as divulgações ambientais e o custo de capital, o que indicaria que a demanda pela sustentabilidade ambiental é relevante para a aquisição da confiança dos investidores e, consequentemente, na obtenção de recursos. Sob essa perspectiva, defendem-se as seguintes hipóteses:

$\boldsymbol{H}_{(1 a)}=O$ capital próprio possui relação positiva e significativa com as práticas ambientais das companhias.

$\boldsymbol{H}_{(\mathbf{l b})}=O$ capital de terceiros possui relação positiva e significativa com as práticas ambientais das companhias.

O pilar Social da RSC aborda quesitos referentes ao tratamento dos funcionários, direitos humanos, relacionamento e impacto na comunidade. Esse pilar foi um dos primeiros a ganhar relevância empresarial, por colocar em debate pela sociedade o bem-estar dos trabalhadores e os direitos humanos, sendo que nos primeiros estudos sobre RSC essa era retratada apensa como responsabilidade social (Campbell, 2007). Com a evolução do termo, o aspecto social continuou com crescentes atenções do público externo por se demonstrar o comprometimento com a melhoria do bem-estar social e das relações com as partes interessadas (Low, 2016).

Cheng et al. (2014) relataram que empresas com desempenho superior no pilar Social possuem menos restrições ao acesso de capital, devido ao maior envolvimento dos stakeholders nas operações das firmas. Cheung, Tan e Wang (2018) confirmaram que empresas com alto nível de desempenho social possuem maior probabilidade de contraírem financiamentos com spreads bancários menores. Santos et al. (2019) encontraram relação positiva e significativa entre a percepção dos funcionários sobre a RSC e o seu engajamento no trabalho, o que impactaria no desempenho financeiro e sucesso organizacional. Com base nisso, formulam-se as hipóteses:

$\boldsymbol{H}_{(2 a)}=O$ capital próprio possui relação positiva e significativa com as práticas sociais das companhias.

$\boldsymbol{H}_{(2 b)}=O$ capital de terceiros possui relação positiva e significativa com as práticas sociais das companhias. 
O pilar da Governança, uma das dimensões mais discutidas na literatura, envolve questões de gestão, estratégias de RSC e tratamento dos shareholders, preocupando-se com os conflitos de agência. Sua importância atribui-se ao mecanismo de monitoramento das ações dos gestores, tal como os esforços das companhias legitimarem-se socialmente responsáveis (Cosenza et al., 2018; Hamrouni et al., 2019). A governança estabelece a distribuição de direitos e responsabilidades dos participantes da empresa, institui regras para a tomada de decisões e fornece estruturas por meio das quais os objetivos da empresa são definidos e monitorados (Villarón-Peramato, Martínez-Ferrero \& García-Sánchez, 2018).

Villarón-Peramato et al. (2018) verificaram que os acionistas exercem pressões para que os gestores adotem práticas de RSC e que tal adoção possui associação positiva com a estrutura de capital. Hamrouni et al. (2019) encontraram relação positiva entre as atividades de governança e o acesso à dividas com terceiros, cujo coeficiente mais significativo foi com o endividamento a longo prazo, demonstrando que essas empresas possuem maior capacidade de endividamento. Assim, formulam-se as hipóteses:

$\boldsymbol{H}_{(3 a)}=O$ capital próprio possui relação positiva e significativa com as práticas de governança das companhias.

$\boldsymbol{H}_{(3 b)}=O$ capital de terceiros possui relação positiva e significativa com as práticas de governança das companhias.

\section{DESENHO DA PESQUISA}

\subsection{População e Amostra}

A população da pesquisa representa as companhias de capital aberto listadas em bolsa de valores com os índices de desempenho ambiental (environment score), social (social score) e governança (governance score) disponibilizados pela Eikon (Refinitiv), no período 20012018, referente aos dez países com maior Produto Interno Bruto (PIB) em 31 de dezembro de 2019. Conforme lista divulgada pelo International Monetary Funds (IMF), os dez países classificados globalmente com maior PIB são: Estados Unidos da América (U\$ 21.439 bilhões), China (U\$ 14.140 bilhões), Japão (U\$ 5.154 bilhões), Alemanha (U\$ 3.863 bilhões), Índia (U\$ 2.963 bilhões), Reino Unido (U\$ 2.744 bilhões), França (U\$ 2.707 bilhões), Itália (U\$ 1.989 bilhões), Brasil (U\$ 1.847 bilhões) e Canadá (U\$ 1.731 bilhões).

Devido à disponibilização dos índices de desempenho das práticas ambientais, sociais e de governança na plataforma Eikon, o recorte inicia a partir de 2001. Ademais, para obtenção da amostra, foram excluídas as empresas do setor financeiro, o que resultou um total de 1.692. Foram descartadas empresas com patrimônio líquido negativo, totalizando na amostra final 1.679 companhias representadas por 22.072 observações.

A amostra de 1.679 empresas foi constituída por dez setores econômicos: bens industriais (350), consumo cíclico (330), materiais básicos (206), tecnologia da informação (163), energia (144), consumo não cíclico (132), imobiliária (119), saúde (107), utilidade pública (93) e telecomunicação (35), e, distribuídas nas dez maiores economia de 2019 na seguinte maneira: Estados Unidos da América (638), China (93), Japão (340), Alemanha (61), Índia (46), Reino Unido (203), França (75), Itália (22), Brasil (32) e Canadá (169).

\subsection{Variáveis da pesquisa}

Para mensurar o desempenho das práticas ambientais, sociais e de governança, este estudo utiliza como proxy os pilares disponibilizados pela Refinitiv (2019), respectivamente: environment score, social score e governance score. Cada índice foi obtido pela ponderação dos 178 indicadores, comparáveis e relevantes do setor, que por sua vez foram selecionados entre as 400 métricas calculadas por meio da coleta de dados ao nível da empresa. Desse modo, observa-se que os índices de tais pilares refletem o desempenho das práticas ambientais, sociais 
e de governança corporativa com base em informações divulgadas publicamente. Na Tabela 1 apresenta-se a ponderação dos pilares da sustentabilidade: o ambiental, o social e a governança.

Tabela 1

Ponderação dos Pilares Ambiental, Social e Governança

\begin{tabular}{|c|c|c|c|}
\hline Pilares & Categorias & $\mathbf{N}^{\circ}$ de Indicadores & Pesos \\
\hline \multirow{4}{*}{ Ambiental } & Utilização de Recursos & 19 & $32 \%$ \\
\hline & Emissões & 22 & $36 \%$ \\
\hline & Inovação & 20 & $32 \%$ \\
\hline & Total & 61 & $100 \%$ \\
\hline \multirow{5}{*}{ Social } & Força de trabalho & 29 & $45 \%$ \\
\hline & Direitos Humanos & 8 & $12 \%$ \\
\hline & Comunidade & 14 & $23 \%$ \\
\hline & Responsabilidade Produto & 12 & $20 \%$ \\
\hline & Total & 63 & $100 \%$ \\
\hline \multirow{4}{*}{ Governança } & Gestão & 34 & $62 \%$ \\
\hline & Acionistas & 12 & $23 \%$ \\
\hline & Estratégia RSC & 8 & $15 \%$ \\
\hline & Total & 54 & $100 \%$ \\
\hline
\end{tabular}

Fonte: Refinitiv (2019).

O Pilar Ambiental se constitui por três categorias: utilização de recursos, emissões e inovação. A utilização de recursos mensura o desempenho e a capacidade da empresa em reduzir o emprego de material, energia e água; as emissões representam o compromisso e o esforço da empresa na redução efetiva de emissões de poluentes; e, a inovação corresponde às novas técnicas, processos ou produtos ecologicamente corretos (Refinitiv, 2019). Estudos revelaram que indústrias poluentes enfrentam maiores pressões externas, obrigando-as a se envolverem estrategicamente em atividades de práticas ambientais, sociais e de governança para melhorar sua reputação e o valor da empresa (Cai et al., 2012).

O Pilar Social é formado por quatro categorias: força de trabalho, direitos humanos, comunidade e responsabilidade pelo produto. A categoria força de trabalho refere-se à eficácia da empresa em garantir saúde e segurança, satisfação no trabalho, diversidade e igualdade; os direitos humanos refletem o respeito pelos trabalhadores; a comunidade representa o compromisso pela cidadania, com padrões éticos e proteção à saúde pública; a responsabilidade do produto refere-se à capacidade de produção por bens e serviços de qualidade e segurança que não infrinjam a integridade ou a privacidade (Refinitiv, 2019).

O Pilar Governança envolve as categorias: gestão, acionistas e estratégia de Responsabilidade Social Corporativa (RSC). A gestão é representada pelas boas práticas de governança corporativa; a categoria dos acionistas refere-se à equidade de tratamento aos acionistas e às medidas de anti-takeover; $\mathrm{e}$, a estratégia de RSC corresponde à comunicação da empresa e sua integração aos aspectos econômicos, sociais e ambientais em suas operações.

$\mathrm{Na}$ Tabela 2 apresenta-se o detalhamento das variáveis utilizadas para este estudo.

Tabela 2

Definição das variáveis

\begin{tabular}{|c|c|}
\hline Variáveis & Operacionalização \\
\hline Dependentes & \\
\hline AMB_score & $\begin{array}{l}\text { Utilização de Recursos x 32\% + Emissões x 36\% + Inovação x 32\% (Refinitiv, 2019). Fonte: } \\
\text { Eikon }\end{array}$ \\
\hline SOC_score & $\begin{array}{l}\text { Força de Trabalho x } 45 \%+\text { Direitos Humanos x } 12 \%+\text { Comunidade x } 23 \%+\text { Responsabilidade } \\
\text { Produto x } 10 \% \text { (Refinitiv, 2019). Fonte: Eikon }\end{array}$ \\
\hline GOV_score & Gestão x $62 \%$ + Acionistas x 23\% + Estratégias RSC x 15\% (Refinitiv, 2019). Fonte: Eikon \\
\hline
\end{tabular}




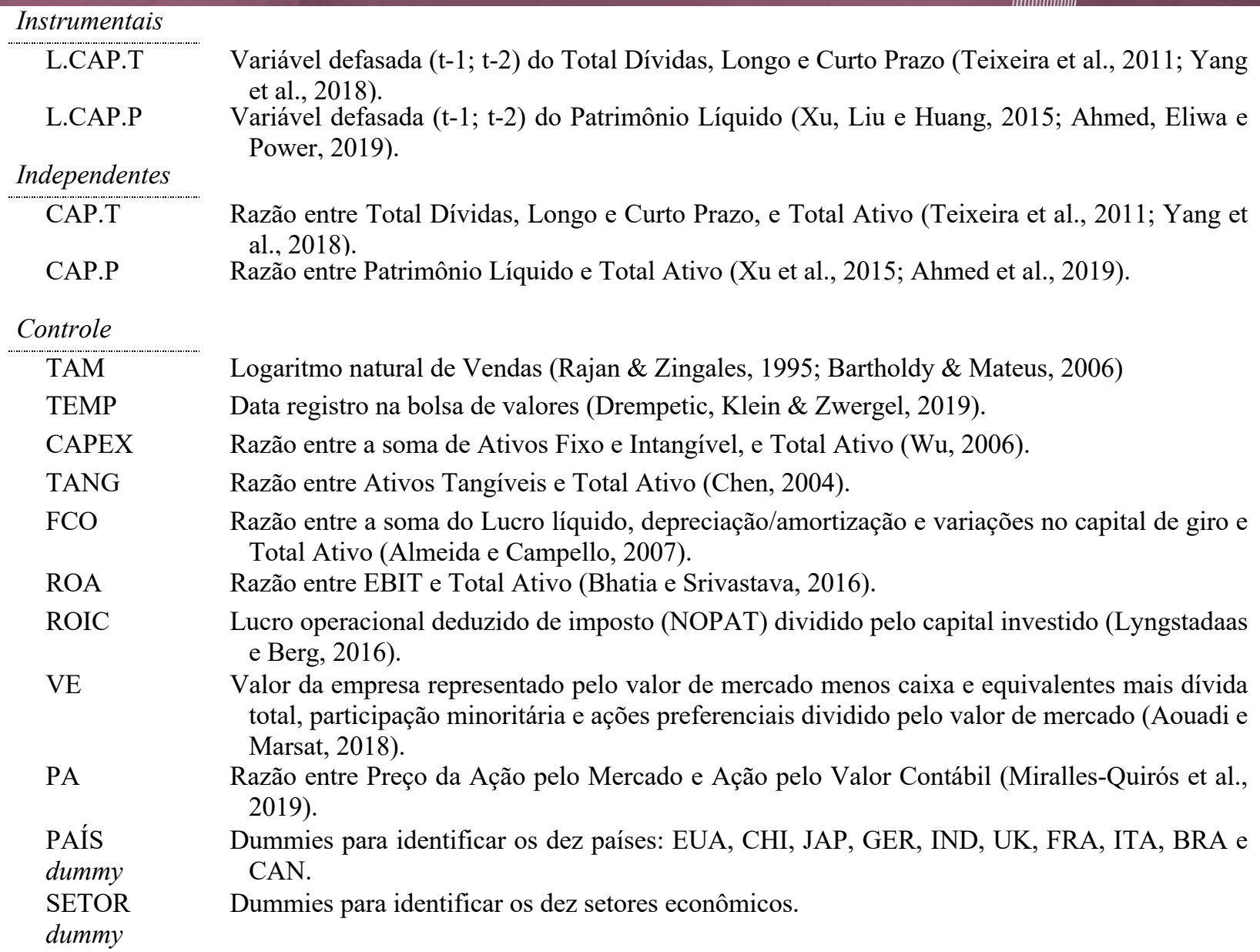

Notas. AMB_score (índice ambiental), SOC_score (índice social), GOV_score (índice de governança), CAP.T (Capital de Terceiros), CA-P.P (Capital Próprio), TAM (tamanho), TEMP (tempo data registro bolsa), CAPEX (capital expenditures), TANG (tangibilidade), FCO (fluxo de caixa operacional), ROA (retorno sobre ativo), ROIC (retorno sobre capital investido); VE (Valor histórico da empresa divido pelo valor de mercado), PVCA (Preço da Ação ao Valor Contábil) L.CAP.P e L.CAP.T (variáveis instrumentais, defasadas); PAÍS (variável dummy para país); e, SETOR (variável dummy para setor econômico). Fonte: dados da pesquisa (2020).

\subsection{Modelo econométrico}

Com base na revisão da literatura, a análise da relação entre estrutura de capital e responsabilidade social corporativa deste estudo será desenvolvida por meio dos modelos econométricos evidenciados nas equações (1a, 1b, 2a, 2b, 3a e 3b):

Ambiental $_{i, t}$, Social $_{i, t}$, Governança $_{i, t}$

$$
\begin{aligned}
& =\beta_{0}+\beta_{1} \text { Capital de Terceiros }_{i, t}+\beta_{2} \text { Instrumental }_{i, t-1}+\sum_{k=3}^{11} \delta_{k} \text { Controls }_{k, t} \\
& +\beta_{12} \text { Setor }_{i, t}+\beta_{13}{\text { Paí } s_{i, t}+\mu_{i, t}}
\end{aligned}
$$

(eq. 1a, 2a e 3a )

Ambiental $_{i, t}$, Social $_{i, t}$, Governança $_{i, t}$

$$
\begin{aligned}
& =\beta_{0}+\beta_{1} \text { Capital Próprio }_{i, t}+\beta_{2} \text { Instrumental }_{i, t-1}+\sum_{k=3}^{11} \delta_{k} \text { Controls }_{k, t} \\
& +\beta_{12} \text { Setor }_{i, t}+\beta_{13}{\text { País } \text { s }_{i, t}+\mu_{i, t}}
\end{aligned}
$$

(eq. 1b, 2b e 3b)

Dessa forma, para um painel curto, em que $\mathrm{T}<\mathrm{N}$, Fávero (2013) relata que uma estimação com erros-padrão robustos clusterizados é conseguida ao considerar o pressuposto 
de que os erros são independentes entre indivíduos e que $\mathrm{N} \rightarrow \infty$, ou seja, que $\left(\varepsilon_{i, t}, \varepsilon_{j, s}\right)=0$ para $\mathrm{i} \neq \mathrm{j}$, que $\mathrm{E}\left(\varepsilon_{i, t}, \varepsilon_{j, s}\right)$ não seja restrita e que $\varepsilon_{i, t}$ seja heterocedástico. A etapa inicial para a aplicação de um modelo com dados em painel, segundo Cameron e Trivedi (2009), é a aplicação de um modelo POLS (pooled ordinary least squares), que assume os regressores exógenos e o termo de erro $\mu_{i, t}$, em vez da decomposição $\alpha_{i}+\varepsilon_{i, t}$, conforme demonstrado na equação (4):

$$
y_{i, t}=\beta_{0}+x_{i, t}^{\prime} \beta_{1}+\mu_{i, t}
$$

(eq. 4)

Os parâmetros desse modelo são estimados por meio de OLS, mas a inferência requer que haja controle da correlação within do erro $\mu_{i, t}$ para um dado indivíduo, a ser elaborado utilizando-se erros-padrão robustos com agrupamento no nível do indivíduo. Nesse contexto, o pressuposto da exogeneidade entre as variáveis é fundamental para inferências adequadas sobre a relação de causalidade. Em razão da invalidade na premissa de não-correlação, constata-se que um ou mais regressores são endógenos, causando viés nos estimadores e inferências equivocadas. Questões de endogeneidade normalmente despontam por três motivos: variáveis omitidas, erros de mensuração dos regressores e/ou simultaneidade (Ketokivi \& McIntosh, 2017).

A proposta deste estudo foi examinar a relação entre os índices de desempenho das práticas ambientais, sociais e de governança e a estrutura de capital, representado pelo Capital Próprio e Capital de Terceiros, utilizando um estimador de painel dinâmico no método de momentos generalizado (GMM), o qual elimina as principais fontes de endogeneidade inerentes às estimações propostas, conforme estudos de Wintoki, Linck e Netter (2012).

\section{ANÁLISE DOS RESULTADOS}

Os testes aplicados após a regressão não mostraram presença de colinearidade nas seis equações [VIF mean $=1,26]$, porém os resíduos apresentaram heterocedasticidade. Assim, foi executado novamente a estimação pelo método POLS com erros-padrão robustos clusterizados para correção da heterocedasticidade. No entanto, considerando que as variáveis dependentes, pilar Ambiental, pilar Social e o pilar de Governança apresentam continuidade no tempo, ou seja, valores passados explicam valores presentes e futuros, é necessário encontrar um método que solucione a questão da endogeneidade. Foram realizados testes de endogeneidade nas seis equações, as quais demonstraram a presença de endogeneidade nas variáveis. Em razão disso, além de utilizar o estimador GMM adequado para painel curto, adotou-se a especificação do modelo com variáveis instrumentais, operando nas variáveis capital de terceiros e capital próprio a defasagem de um e dois períodos na especificação dinâmica. Desse modo, o método dos momentos generalizado torna-se uma alternativa incontestável para a estimação consistente dos parâmetros (Baum, Schaffer \& Stillman, 2007; Roodman, 2009).

Dada a questão da endogeneidade entre as variáveis e a heterocedasticidade encontrada nos resíduos, os resultados estatísticos consistentes correspondem ao GMM a dois estágios pelo método robusto. Os resultados das estimação GMM 2SLS estão evidenciados na Tabela 3. 
Tabela 3

Resultados das Estimações GMM 2SLS

\begin{tabular}{|c|c|c|c|c|c|c|}
\hline \multirow{2}{*}{$\begin{array}{l}\text { Variável Dependente } \\
\text { Estimador GMM } 2 S L S\end{array}$} & \multicolumn{2}{|c|}{ Ambiental } & \multicolumn{2}{|c|}{ Social } & \multicolumn{2}{|c|}{ Governança } \\
\hline & Coef. Sig. & Coef. & Coef. Sig. & Coef. & Coef. Sig. & Coef. \\
\hline Capital Próprio & $\mathbf{5 , 4 0}$ & & $\mathbf{6 , 5 7} 7^{* * *}$ & & $2,79^{* * *}$ & \\
\hline Capital de Terceiros & & $-4,52^{* * *}$ & & $-2,66^{* *}$ & & $-1,13$ \\
\hline Tamanho & $7,26^{* * *}$ & $7,07^{* * *}$ & $7,05^{* * *}$ & $6,79^{* * *}$ & $4,33^{* * *}$ & $4,22^{* * *}$ \\
\hline Tempo & $0,13^{* * *}$ & $0,12^{* * *}$ & $0,15^{* * *}$ & $0,15^{* * *}$ & $0,10^{* * *}$ & $0,10^{* * *}$ \\
\hline CAPEX & $5,80^{* * *}$ & $6,48^{* * *}$ & 2,67 & 3,07 & $3,52^{* * *}$ & $3,68^{* * *}$ \\
\hline Tangibilidade & $-8,36^{* * *}$ & $-8,30^{* * *}$ & $-13,34^{* * *}$ & $-12,43^{* * *}$ & $-9,39^{* * *}$ & $-9,00^{* * *}$ \\
\hline F. Caixa Operacional & $-20,04^{* * *}$ & $-20,27^{* * *}$ & $-3,03^{* * *}$ & $-2,53^{* * *}$ & $-18,90^{* * *}$ & $-18,65^{* * *}$ \\
\hline ROA & 2,36 & 2,59 & $8,51^{* * *}$ & $9,07^{* * *}$ & $8,27^{* * *}$ & $8,50^{* * *}$ \\
\hline ROIC & 0,02 & 0,01 & 0,03 & 0,02 & 0,03 & 0,03 \\
\hline Valor Empresa & $-0,36^{* * *}$ & $-0,37^{* * *}$ & $-0,39^{* * *}$ & $-0,49^{* * *}$ & $-0,31^{* *}$ & $-0,36^{* * *}$ \\
\hline Preço da Ação & 0,00 & 0,00 & $0,00^{*}$ & $0,00^{* *}$ & 0,00 & 0,00 \\
\hline intercepto & $-117^{* * *}$ & $-109^{* * *}$ & $-111^{* * *}$ & $-102^{* * *}$ & $-47^{* * *}$ & $-43^{* * *}$ \\
\hline \multicolumn{7}{|l|}{ USA } \\
\hline CHI & $-11,82^{* * *}$ & $-11,89^{* * *}$ & $-16,86^{* * *}$ & $-16,80^{* * *}$ & $-2,26^{* * *}$ & $-2,25^{* * *}$ \\
\hline JAP & $1,71^{* * *}$ & $1,84^{* * *}$ & $-11,68^{* * *}$ & $-11,30^{* * *}$ & $-6,18^{* * *}$ & $-6,02^{* * *}$ \\
\hline GER & 8,65 & $8,29^{* * *}$ & $7,80^{* * *}$ & $7,51^{* * *}$ & $-4,73^{* * *}$ & $-4,85^{* * *}$ \\
\hline IND & $9,58^{* * *}$ & $9,68^{* * *}$ & $9,34^{* * *}$ & $9,56^{* * *}$ & 0,19 & 0,28 \\
\hline UK & $15,14^{* * *}$ & $14,91^{* * *}$ & $10,76^{* * *}$ & $10,55^{* * *}$ & $3,28^{* * *}$ & $3,19^{* * *}$ \\
\hline FRA & $19,65^{* * *}$ & $19,51^{* * *}$ & $11,54^{* * *}$ & $11,42^{* * *}$ & $-3,58^{* * *}$ & $-3,64^{* * *}$ \\
\hline ITA & $12,69^{* * *}$ & $12,49^{* * *}$ & $15,45^{* * *}$ & $15,11^{* * *}$ & $4,06^{* * *}$ & $3,91^{* * *}$ \\
\hline BRA & $12,41^{* * *}$ & $12,53^{* * *}$ & $12,46^{* * *}$ & $12,56^{* * *}$ & $-0,05$ & 0,00 \\
\hline CAN & $3,89^{* * *}$ & $3,89^{* * *}$ & $4,14^{* * *}$ & $4,21^{* * *}$ & $4,33^{* * *}$ & $4,36^{* * *}$ \\
\hline \multicolumn{7}{|l|}{ Materiais básicos } \\
\hline Consumo cíclico & $-2,76^{* * *}$ & $-2,84^{* * *}$ & $-1,59^{* * *}$ & $-1,68^{* * *}$ & $-4,92^{* * *}$ & $-4,96^{* * *}$ \\
\hline Consumo não-cíclico & $-5,45^{* * *}$ & $-5,53^{* * *}$ & $-3,47^{* * *}$ & $-3,59^{* * *}$ & $-2,42^{* * *}$ & $-2,47^{* * *}$ \\
\hline Energia & $-0,47$ & $-0,45$ & $-0,56$ & $-0,41$ & $1,22^{*}$ & $1,29^{* *}$ \\
\hline Imobiliário & $9,37^{* * *}$ & $9,56^{* * *}$ & $10,85^{* * *}$ & $10,75^{* * *}$ & 0,13 & 0,09 \\
\hline Saúde & $1,51^{* * *}$ & $1,85^{* * *}$ & $3,28^{* * *}$ & $3,67^{* * *}$ & $3,22^{* * *}$ & $3,39^{* * *}$ \\
\hline Indústria & $-3,13^{* * *}$ & $-3,39^{* * *}$ & $-1,85$ & $-2,24^{* * *}$ & $-3,04^{* * *}$ & $-3,20^{* * *}$ \\
\hline Tecnologia Informação & $5,17^{* * *}$ & $5,26^{* * *}$ & $6,08^{* * *}$ & $6,27^{* * *}$ & $2,14^{* * *}$ & $2,22^{* * *}$ \\
\hline Telecomunicações & $-5,73^{* * *}$ & $-5,57^{* * *}$ & $-6,55^{* * *}$ & $-6,56^{* * *}$ & $-1,95^{*}$ & $-1,95^{*}$ \\
\hline Utilidade Pública & $-4,30^{* * *}$ & $-4,64^{* * *}$ & $-5,88^{* * *}$ & $-6,45^{* * *}$ & $-0,10$ & $-0,34$ \\
\hline $\mathrm{R}^{2}=$ & 0,32 & 0,31 & 0,34 & 0,33 & 0,12 & 0,12 \\
\hline $\operatorname{chi}^{2}=$ & 11308 & 11363 & 11156 & 11212 & 3186 & 3188 \\
\hline
\end{tabular}

Notas. $(*)$ p-value $<0,01,(* *)$ p-value $<0,05,(* * *)$ p-value $<0,10$. Fonte: dados da pesquisa $(2020)$.

USA - Estados Unidos da América, CHI - China, JAP - Japão, GER - Alemanha, IND - Índia, UK - Reino Unido, FRA França, ITA - Itália, BRA - Brasil, CAN - Canadá.

Os resultados na Tabela 3 demonstram que os parâmetros e sinais do capital próprio e capital de terceiros relacionados distintamente com os índices Ambiental, Social e de Governança, diferem entre si. Em primeira análise, observa-se que o capital próprio apresentou significância estatística e relação positiva com todos os pilares que compõe a RSC. Tais achados são consistentes com os pressupostos deste estudo em relação às $H_{(1 a)}, H_{(2 a)}$ e $H_{(3 a)}$, nos quais se deduz que o desempenho dos três índices que formam a RSC depende da fonte de financiamento dos acionistas, em consonância com Eding e Scholtens (2017).

Ressalta-se nessa inferência, as pressões exercidas pelos stakeholders na obtenção de reputação corporativa positiva como também a geração de capital moral pelo desempenho do triple-bottom line. Essas pressões moderam a relação entre o desempenho Ambiental, Social e de Governança e o capital próprio, ou seja, a intensidade de tais pressões se reflete nos índices da RSC que, por sua vez, demanda investimento para o desempenho corporativo socialmente responsável. Ao implementar estratégias ambientais, sociais e de governança, as organizações necessitam de investimentos para comprar equipamentos e/ou maquinários que possam garantir 
maior segurança do produto, proteção ambiental e social. Com a adoção de tais políticas, as empresas se destacarão pela sua imagem social entre aquelas que não as adotam (Godfrey, Merrill \& Hansen 2009; Yang et al., 2018).

Outro aspecto importante a notar são os parâmetros distintos do capital próprio em relação aos três pilares, Ambiental $(5,40)$, Social $(6,57)$ e de Governança $(2,79)$. Isso significa que a cada acréscimo na fonte de financiamento dos acionistas, o índice Ambiental aumenta 5,4 vezes, o Social 6,57 vezes e a Governança 2,79 vezes. A peculiaridade evidente encontrada no índice de Governança quando relacionado ao capital próprio reside no fato que o crescimento do seu desempenho ocorre gradualmente, exigindo disponibilidade maior dos acionistas. Ao passo que, os índices Social e Ambiental alcançam níveis de desempenho maiores com menor exigência do capital próprio. Essa descoberta ratifica a percepção de que ultimamente, as empresas enfrentam crescentes pressões sociais e normativas para agir de maneira socialmente responsável, exigindo níveis melhores dos índices de RSC junto ao desempenho financeiro (Campbell, 2007; Ali et al., 2014).

Ainda, outra razão para a demanda elevada de capital próprio relacionada ao índice de Governança refere-se à adoção das estratégias de RSC pelas organizações, dado que o retorno dos investimentos efetuados para execução de tais estratégias é de longo prazo. Assim, sob o ponto de vista dos investidores, se as companhias diminuem o risco a longo prazo com a adoção dessas práticas, esses estarão dispostos a fornecer um maior capital para a obtenção de retorno financeiro (Yang et al., 2018).

Para exemplificar graficamente, as três relações discutidas estão demonstradas na Figura 1 (índice Ambiental e capital próprio), Figura 2 (índice Social e capital próprio) e Figura 3 (índice Ambiental e capital próprio). Em tais gráficos foram consideradas as empresas italianas e japonesas do setor de Tecnologia da Informação.

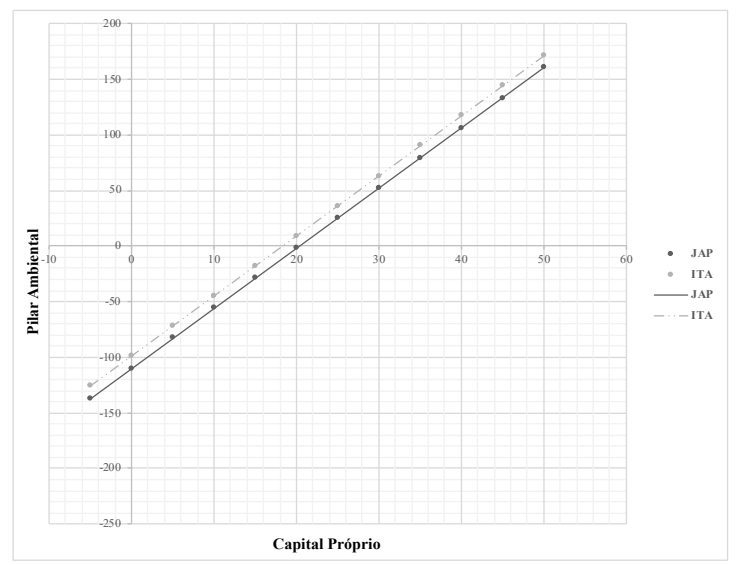

Figura 1. Índice Ambiental e capital próprio do Japão e Itália - setor de TI. Fonte: dados da pesquisa (2020).

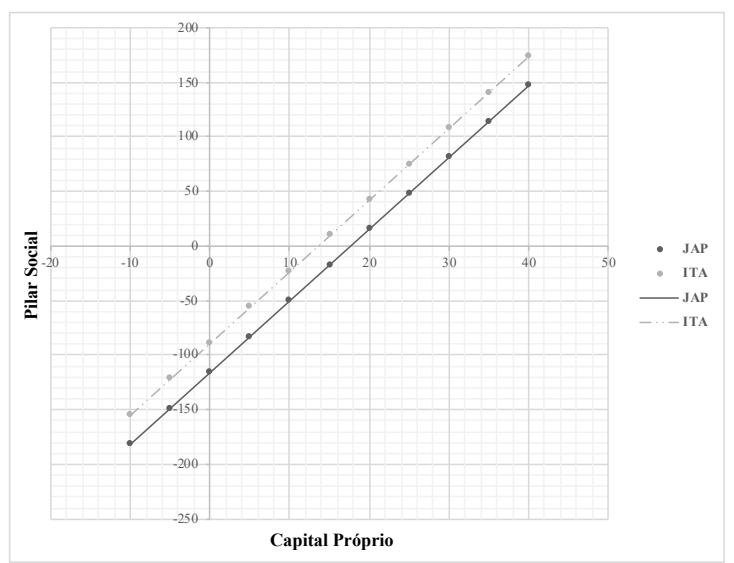

Figura 2. Índice Social e capital próprio do Japão e Itália - setor de TI. Fonte: dados da pesquisa (2020).

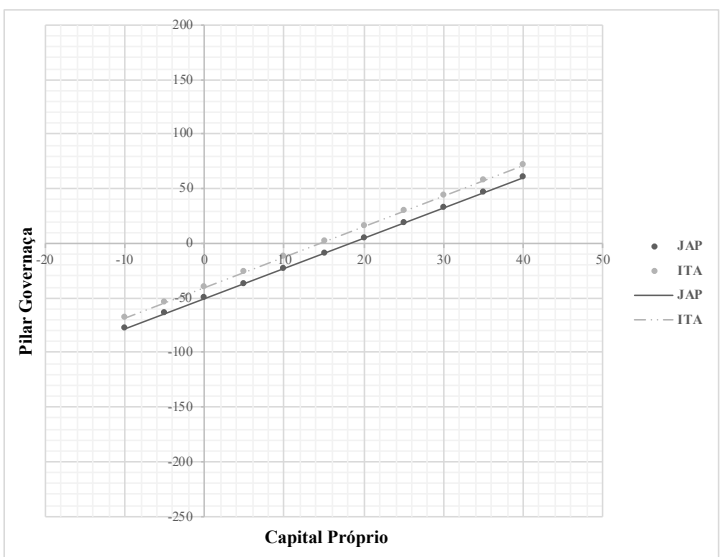

Figura 3. Índice de Governança e capital próprio do Japão e Itália - setor de TI. Fonte: dados da pesquisa (2020). 
As três relações apresentadas nos gráficos são positivas entre o índice Ambiental e capital próprio (Figura 1), o índice Social e capital próprio (Figura 2) e o índice de Governança e capital próprio (Figura 3). Para as empresas italianas, os pilares da RSC exigem menor financiamento dos acionistas que as empresas japonesas, no setor da tecnologia da informação. Isso demonstra a existência de particularidades entre os três pilares entre países.

Em relação ao capital de terceiros, a primeira característica em evidência no resultado apresentado na Tabela 2 são os sinais que, diversamente daqueles revelados no capital próprio, são negativos para todos os índices da RSC. Sendo que, somente com o índice de Governança não foi encontrado significância estatística. Nessa relação inversa entre o capital de terceiros e os índices Ambiental, Social e de Governança, cabe observar que o crescimento no desempenho dos índices de RSC, significa uma redução na utilização de financiamento contraído com terceiros. Apesar da significância estatística, esse achado conduz à rejeição das $H_{(1 b)}, H_{(2 b)} \mathrm{e}$ $H_{(3 b)}$, as quais predizem uma relação positiva e significativa.

Possíveis explicações para essa relação inversa, caracterizada entre o capital de terceiros e os índices de RSC, envolve os seguintes raciocínios: (i) sob pressão exercida pelos stakeholders, as empresas mantém uma dívida reduzida com terceiros devido à aversão ao risco, e assim, reduzir a preocupação das partes interessadas (Titman \& Wessels, 1988; Kale \& Shahrur, 2007); (ii) as partes interessadas têm incentivo para realizar investimentos específicos da empresa para afetar as decisões de financiamento de uma empresa (Titman, 1984); (iii) empresas preocupadas com benefício social têm maior aversão ao risco; (iv) firmas com participação societária governamental mantém as dívidas com terceiros a nível reduzido. E, por fim, a existência da preferência pelo capital próprio como fonte de financiamento para mitigar os riscos. Uma vez ampliado a captação de recursos por meio dos acionistas, consequentemente há uma redução no capital de terceiros. Essas evidências revelam que a implementação e manutenção das estratégias de RSC são sinais que reduzem as informações assimétricas entre gestores e investidores (Cho et al., 2013; Chen et al., 2018). Na Figura 4 são apresentados graficamente os resultados das empresas brasileiras e chinesas, do setor de materiais básicos, entre o capital de terceiros e o índice Ambiental.

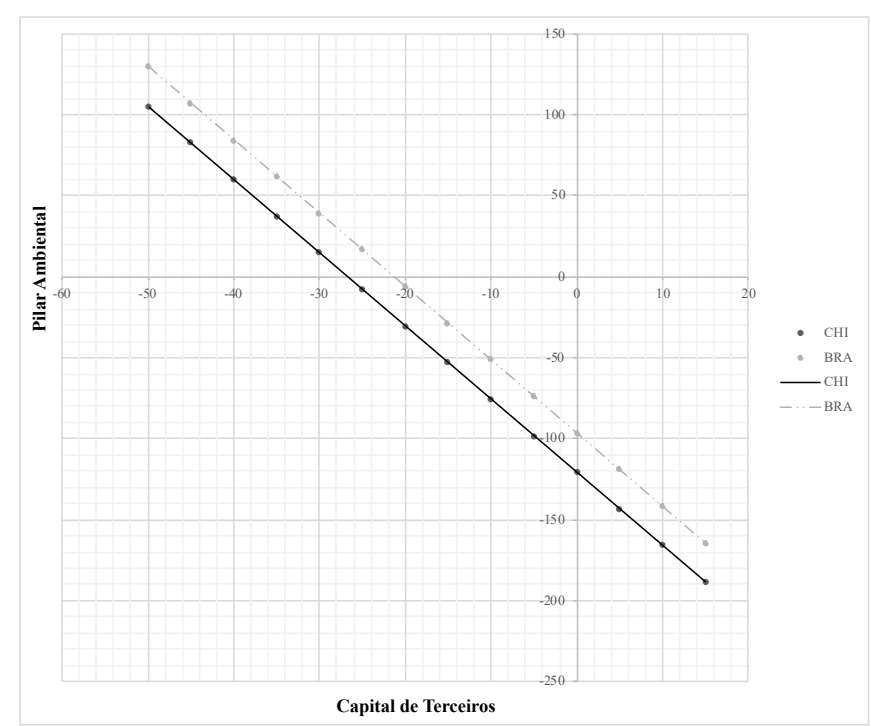

Figura 4. Índice Ambiental e Capital de Terceiros do Brasil e China para o setor de materiais básicos. Fonte: dados da pesquisa (2020).

Para efeitos de comparação, cabe notar que o intercepto para as empresas do Brasil e da China, no setor de materiais básicos, equivalem a $-109+12,53=-96,47$ e $-109+$ $(-11,89)=-120,89$, respectivamente. Embora as empresas chinesas demonstram uma redução 
maior no capital de terceiros, o desempenho do índice ambiental é menor que a empresas brasileiras, as quais evidenciam redução menor na fonte de financiamento de terceiros. $\mathrm{O}$ gráfico da Figura 4 demonstra a relação inversa entre o índice de desempenho Ambiental e o capital de terceiros, em outras palavras, as dívidas contraídas com terceiros diminuem ao aumentar o índice Ambiental. Os índices de RSC são compelidos por leis e sistemas, bem como pela pressão da sociedade e meio ambiente. São também instigados para aumentar lucros, sofisticar as habilidades competitivas, motivar funcionários e valorizar a reputação corporativa. Sofrem pressões por fatores internos e externos, diferenciando-se pelos ambientes culturais e de sistema (Mzembe \& Meaton, 2014).

Quanto às variáveis de controle tangibilidade e do fluxo de caixa operacional revelam sinais negativos, apresentando dessa maneira uma relação inversa com o desempenho das práticas ambientais, sociais e de governança. Em outras palavras, ao desenvolver tais práticas, as empresas utilizam os recursos tangíveis e operacionais do fluxo de caixa. Nas práticas ambientais e de governança, nota-se maior utilização dos ativos tangíveis, ao passo que nas práticas sociais, os recursos de fluxo de caixa operacional. Quanto ao CAPEX, representado pela compra/aquisição de ativo tangíveis e intangíveis, o resultado estatístico obtido demonstra significância ao nível de $1 \%$ e relação positiva com todas as práticas de RSC. Percebe-se que ao aumentar investimentos na compra/aquisição de propriedades, terrenos, equipamentos, software etc., consequentemente as empresas impulsionam as práticas ambientais, sociais e de governança.

Por outro lado, o retorno sobre o ativo (ROA) não apresentou significância estatística com as práticas ambientais, entretanto o demonstrou ao nível de $1 \%$ com as práticas sociais e de governança como apresentado nos estudos de Xiao et al. (2018). Os autores argumentam que empresas pertencentes a países com níveis altos de desempenho em sustentabilidade geralmente reputam mais difícil capitalizar o desempenho em sustentabilidade corporativa que empresas de países com níveis relativamente baixos no desempenho social corporativo. Já o retorno sobre capital investido (ROIC) não apresentou significância e o preço da ação ao valor contábil apresentou relação positiva e significância estatística somente com as práticas sociais. $\mathrm{O}$ tamanho e o tempo de registro das empresas revelaram relação positiva e significativa com os três índices de RSC e capital próprio e de terceiros.

De modo particular, ressalta-se a correlação negativa e significância estatística a $1 \%$ da variável valor da empresa com os índices de desempenho das práticas ambientais, sociais e de governança. Na operacionalização dessa variável conforme demonstrada na Equação 5:

$$
V E=\frac{(V M-C x E q)+(C P . T+I M+A P)}{V M}
$$

Em que VE (Valor da Empresa), VM (Valor do Mercado, CxEq (Caixa e Equivalente), CP.T (Capital de Terceiros), IM (interesse minoritário) e AP (ações preferenciais), onde verifica-se que a presença do capital de terceiros pode ter influenciado negativamente a correlação em questão. Essa mesma relação foi encontrada nos achados de Aouadi e Marsat (2018).

Em relação aos dez países, nota-se significância em todos os países ao nível de 1\% para as práticas ambientais, sociais e de governança, com exceção do Brasil e da Índia que não apresentou significância em relação ao índice de governança. Do mesmo modo, os dez setores econômicos apresentaram significância no modelo, porém o setor da energia apresentou significância ao nível de $10 \%$ somente com as práticas de governança enquanto os setores imobiliários e de utilidade pública não apresentaram significância nas práticas de governança. Nessa linha investigativa, os estudos de Allouche e Laroche (2005), ao executarem a metaanálise em trabalhos sobre os efeitos de práticas ambientais, sociais e de governança no 
desempenho financeiro das empresas, demonstram a relevância da identificação dos setores econômicos e países no modelo econométrico. Igualmente, McWilliams et al. (2006) e Garcia et al. (2019) revelaram a importância da qualificação do país, região e o ramo de atuação dos negócios das empresas em estudos que tratam dessas práticas de sustentabilidade.

As empresas chinesas, americanas e japonesas necessitam de investimentos maiores em relação às outras para obter um índice Ambiental e Social positivo. Por sua vez, em relação ao índice de Governança são as empresas japonesas, alemãs e francesas que demandam maior exigência de capital. Enquanto, de maneira oposta, as empresas que demandam investimentos menores para obter índices positivos Ambiental, Social e de Governança são, respectivamente as francesas, italianas e canadenses.

\section{CONSIDERAÇÕES FINAIS}

As recentes mudanças de pensamentos difundidas mundialmente em prol do meio ambiente e das questões sociais conduzem as partes interessadas a exercer pressões nas organizações para que essas assumam comportamentos socialmente responsáveis. Consequentemente, a fim de obter níveis adequados de RSC, as fontes de financiamento, seja próprio ou de terceiros, tornam-se fundamentais. De forma que, este artigo investigou a influência do capital próprio e o de terceiros nos pilares da responsabilidade social corporativa.

Os resultados do estudo indicam diferenças entre a relação do capital próprio e o de terceiros com os índices da RSC. Sobre o primeiro, constatou-se uma relação positiva e significativa entre as práticas ambientais, sociais e de governança, conduzindo a não rejeição das hipóteses $\mathrm{H}_{(1 \mathrm{a})}, \mathrm{H}_{(2 \mathrm{a})}$ e $\mathrm{H}_{(3 \mathrm{a})}$. Quanto ao segundo, os sinais obtidos em seus parâmetros são negativos na relação com cada pilar da RSC, sugerindo portanto a rejeição das hipóteses $\mathrm{H}_{(1 \mathrm{~b})}$, $\mathrm{H}_{(2 b)}$ e $\mathrm{H}_{(3 b)}$, uma vez que essas aludiam a uma associação positiva e significativa. Além disso, foi encontrado contrastes entre a influência do capital próprio e de terceiros em cada país e setor de atuação das empresas.

Uma das contribuições desta pesquisa consiste justamente na identificação da relação diferenciada entre os índices de RSC e o capital próprio e de terceiros. De modo particular, cabe ressaltar que as pressões exercidas pelas partes interessadas sobre as empresas se traduzem na relação inversa entre o capital de terceiros e as práticas ambiental, social e de governança. Compreende-se que essa consequência advém da associação positiva entre o capital próprio e os índices estudados. Isso porque, em altos níveis de RSC, as companhias obtêm maior acesso a financiamentos, porém devido ao baixo risco e custo de capital, essas dão prioridade ao financiamento de suas atividades com o capital próprio.

Fica claro que a possibilidade de financiamento com capital próprio provém da satisfação das expectativas dos acionistas sobre as práticas de RSC, o que gera imagem positiva e aumento da reputação corporativa - a qual produz impactos em diferentes áreas das companhias. Por vezes, as estratégias de RSC também são utilizadas para melhorar o ambiente e reduzir o risco corporativo, devido a sua contribuição para o aprimoramento do relacionamento entre a empresa e as suas partes interessadas. Portanto, esclarece-se que o envolvimento em estratégias de RSC traz consequências positivas para as organizações, argumento este relacionado à reputação corporativa.

Outra contribuição a salientar é que, ao comparar com o índice de governança, o desempenho dos índices social e ambiental demandam investimentos menores dos acionistas. Tal fato se dá pelos custos elevados das estratégias de RSC, presentes no índice de governança. Ao inferir que as organizações não necessariamente precisam desembolsar grandes valores para obter resultados positivos nas dimensões sociais e ambientais - essa descoberta pode incentivar as organizações a ampliarem o desenvolvimento das práticas de RSC e assim, preservar o ambiente em que se vive. 
Diante dos achados deste estudo, pesquisas futuras ainda podem ir além. Apesar da nossa lente teórica sobre as pressões existentes a favor da RSC, sugere-se investigações que verifiquem se as práticas sociais responsáveis das organizações são proativas ou reativas a essas pressões. Concomitantemente, incentiva-se a verificação da existência de incentivos dos Governos para o aumento de práticas de RSC, analisando as diferenças entre países e regiões.

$\mathrm{Na}$ atual conjectura das discussões mundiais acerca dos impactos sociais e ambientais, defende-se aqui que apenas a colaboração entre as organizações, sociedade e governo podem melhorar as expectativas sobre o futuro. À vista disso, a academia também deve se envolver nesses debates, trazendo evidências e reflexões, a fim de aprimorar os panoramas de ações necessárias para melhorar a vida na terra.

\section{REFERÊNCIAS}

Ahmed, A. H., Eliwa, Y., \& Power, D. M. (2019). The Impact of Corporate Social and Environmental Practices on the Cost of Equity Capital: UK Evidence. International Journal of Accounting \& Information Management, 27(3), 425-441. https://doi.org/10.1108/IJAIM-11-2017-0141

Al-Dah, B., Dah, M., \& Jizi, M. (2018). Is CSR Reporting Always Favorable?. Management Decision, 56(7), 1506-1525. https://doi.org/10.1108/MD-05-2017-0540

Ali, R., Lynch, R., Melewar, T.C., \& Jin, Z. (2014). The Moderating Influences on the Relationship of Corporate Reputation with its Antecedents and Consequences: A MetaAnalytic Review. Journal of Business Research, 68(5), 1105-1117. https://doi.org/10.1016/j.jbusres.2014.10.013

Allouche, J., \& Laroche, P. (2005). A Meta-Analytical Investigation of the Relationship Between Corporate Social and Financial Performance. Revue de Gestion des Ressources Humaines, Eska, 2005, 18-48. Retrieved on December 17, 2019, from https://hal.archives-ouvertes.fr/hal-00923906/

Almeida, H., \& Campello, M. (2007). Financial Constraints, Asset Tangibility, and Corporate Investment. The Review of Financial Studies, 20(5), 1429-1460. https://doi.org/10.1093/rfs/hhm019

Almeida, M. A., \& Santos, J. F. (2016). Capital Structure and Voluntary Disclosure of Information on Corporate Social Responsibility in Brazilian Companies. Revista de Ciências da Administração, 18(45), 109-127. http://dx.doi.org/10.5007/2175$\underline{8077.2016 \mathrm{v} 18 \mathrm{n} 45 \mathrm{p} 109}$

Aouadi, A., \& Marsat, S. (2018). Do ESG Controversies Matter for Firm Value? Evidence From International Data. Journal of Business Ethics, 151(4), 1027-1047. https://doi.org/10.1007/s10551-016-3213-8

Bae, K. H., El Ghoul, S., Guedhami, O., Kwok, C. C., \& Zheng, Y. (2019). Does Corporate Social Responsibility Reduce the Costs of High Leverage? Evidence from Capital Structure and Product Market Interactions. Journal of Banking \& Finance, 100, 135-150. https://doi.org/10.1016/j.jbankfin.2018.11.007

Baraibar-Diez, E., \& Sotorrío, L. L. (2018). O Efeito Mediador da Transparência na Relação entre Responsabilidade Social Corporativa e Reputação Corporativa. Revista Brasileira de Gestão de Negócios, 20(1), 5-21. https://doi.org/10.7819/rbgn.v20i1.3600

Bartholdy, J., \& Mateus, C. (2006). Debt and Taxes: Evidence from Bank-Financed unlisted firms. In: Aarhus School of Business, Finance Research Group, 1-50. Retrieved on December 17, 2019, http://pure.au.dk/portal/files/32345703/F 2006 02.pdf

Baum, C. F., Schaffer, M. E., \& Stillman, S. (2007). Enhanced Routines for Instrumental Variables/Generalized Method of Moments Estimation and Testing. The Stata Journal, 7(4), 465-506. https://doi.org/10.1177/1536867X0800700402 
Bhatia, S., \& Srivastava, A. (2016). Working Capital Management and Firm Performance in Emerging Economies: Evidence from India. Management and Labour Studies, 41(2), 7187. https://doi.org/10.1177/0258042X16658733

Cai, Y., Jo, H., \& Pan, C. (2012). Doing Well While Doing Bad? CSR in Controversial Industry Sectors. Journal of Business Ethics, 108(4), 467-480. https://doi.org/10.1007/s10551011-1103-7

Campbell, J. L. (2007). Why Would Corporations Behave in Socially Responsible Ways? An Institutional Theory of Corporate Social Responsibility. Academy of Management Review, 32(3), 946-967. https://doi.org/10.5465/amr.2007.25275684

Cameron, A. C., \& Trivedi, P. K. (2009). Microeconometrics Using STATA. College Station: Stata Press.

Carroll, A. B. (1979). A Three-Dimensional Conceptual Model of Corporate Performance. Academy of Management Review, 4(4), 497-505. https://doi.org/10.5465/amr.1979.4498296

Carroll, A. B. (2008). A History of Corporate Social Responsibility: Concepts and Practices. In Crane, A., McWilliams, A., Matten, D., Moon, J., \& Siegel, D. (eds.) The Oxford Handbook of Corporate Social Responsibility. Oxford: Oxford University Press, 19-46.

Chakraborty, A., Gao, L. S., \& Sheikh, S. (2019). Managerial Risk-Taking Incentives, Corporate Social Responsibility and Firm Risk. Journal of Economics and Business, 101, 58-72. https://doi.org/10.1016/j.jeconbus.2018.07.004

Chen, J. J. (2004). Determinants of Capital Structure of Chinese-Listed Companies. Journal of Business research, 57(12), 1341-1351. https://doi.org/10.1016/S0148-2963(03)00070-5

Chen, Y. C., Hung, M., \& Wang, Y. (2018). The Effect of Mandatory CSR Disclosure on Firm Profitability and Social Externalities: Evidence from China. Journal of Accounting and Economics, 65(1), 169-190. https://doi.org/10.1016/j.jacceco.2017.11.009

Cheng, B., Ioannou, I., \& Serafeim, G. (2014). Corporate Social Responsibility and Access to Finance. Strategic Management Journal, 35(1), 1-23. https://doi.org/10.1002/smj.2131

Cheung, Y. L., Tan, W., \& Wang, W. (2018). National Stakeholder Orientation, Corporate Social Responsibility, and Bank Loan Cost. Journal of Business Ethics, 150(2), 505-524. https://doi.org/10.1007/s10551-016-3140-8

Cho, S. Y., Lee, C., \& Pfeiffer Jr, R. J. (2013). Corporate Social Responsibility Performance and Information Asymmetry. Journal of Accounting and Public Policy, 32(1), 71-83. https://doi.org/10.1016/j.jaccpubpol.2012.10.005

Clarkson, P. M., Li, Y., Richardson, G. D., \& Vasvari, F. P. (2008). Revisiting the Relation Between Environmental Performance and Environmental Disclosure: An Empirical Analysis. Accounting, Organizations and Society, 33(4-5), 303-327. https://doi.org/10.1016/j.aos.2007.05.003

Cosenza, J. P., Ribeiro, C. M. A., Levy, A., \& Dios, S. A. (2018). CSR Sensemaking on the Collapse of the Samarco's Tailings Dam. Revista de Contabilidade e Organizações, 12(1), 1-16. http://dx.doi.org/10.11606/issn.1982-6486.rco.2018.151356

Dahlsrud, A. (2008). How Corporate Social Responsibility is Defined: an Analysis of 37 Definitions. Corporate Social Responsibility and Environmental Management, 15(1), 113. https://doi.org/10.1002/csr.132

Drempetic, S., Klein, C., \& Zwergel, B. (2019). The Influence of Firm Size on the ESG Score: Corporate Sustainability Ratings Under Review. Journal of Business Ethics, 1-28. https://doi.org/10.1007/s10551-019-04164-1

Eding, E., \& Scholtens, B. (2017). Corporate Social Responsibility and Shareholder Proposals. Corporate Social Responsibility and Environmental Management, 24(6), 648-660. https://doi.org/10.1002/csr.1434 
Fávero, L. P. L. (2013). Dados em Painel em Contabilidade e Finanças: Teoria e Aplicação. Brazilian Business Review, 10(1), 131-156. https://doi.org/10.15728/bbr.2013.10.1.6

Garcia, A. S., Mendes-Da-Silva, W., \& Orsato, R. J. (2019). Corporate Sustainability, Capital Markets, and ESG Performance. In Mendes-Da-Silva, W (org.) Individual Behaviors and Technologies for Financial Innovations. Cham: Springer, 287-309.

Godfrey, P. C., Merrill, C. B., \& Hansen, J. M. (2009). The Relationship Between Corporate Social Responsibility and Shareholder Value: An Empirical Test of the Risk Management Hypothesis. Strategic Management Journal, 30(4), 425-445. https://doi.org/10.1002/smj.750

Gössling, T., \& Vocht, C. (2007). Social Role Conceptions and CSR Policy Success. Journal of Business Ethics, 74(4), 363-372. https://doi.org/10.1007/s10551-007-9512-3

Hamrouni, A., Boussaada, R., \& Ben Farhat Toumi, N. (2019). Corporate Social Responsibility Disclosure and Debt Financing. Journal of Applied Accounting Research, 20(4), 394-415. https://doi.org/10.1108/JAAR-01-2018-0020

Haninun, H., Lindrianasari, L., Sarumpaet, S., Komalasari, A., \& Gunardi, A. (2019). Environmental Disclosure on Cost of Capital: Environmental Risk as a Moderator Variable. Journal of Environmental Management and Tourism, 10(3), 554-561. https://doi.org/10.14505//jemt.v10.3(35).08

International Monetary Funds (IMF). (2019). Retrieved on December 05, 2019, from https://www.imf.org/external/datamapper/NGDPD@WEO/OEMDC/ADVEC/WEOWO $\underline{\mathrm{RLD}}$

Kale, J. R., \& Shahrur, H. (2007). Corporate Capital Structure and the Characteristics of Suppliers and Customers. Journal of Financial Economics, 83(2), 321-365. https://doi.org/10.1016/i.jfineco.2005.12.007

Kanji, G. K., \& Chopra, P. K. (2010). Corporate Social Responsibility in a Global Economy. Total Quality Management, $\quad$ 21(2), 119-143. https://doi.org/10.1080/14783360903549808

Ketokivi, M., \& McIntosh, C. N. (2017). Addressing the Endogeneity Dilemma in Operations Management Research: Theoretical, Empirical, and Pragmatic Considerations. Journal of Operations Management, 52, 1-14. https://doi.org/10.1016/j.jom.2017.05.001

Kraus, P., \& Brtitzelmaier, B. (2012). A Literature Review on Corporate Social Responsibility: Definitions, Theories and Recent Empirical Research. International Journal of Management Cases, 14(4), 282-296. https://doi.org/10.5848/APBJ.2012.00105

Lyngstadaas, H., \& Berg, T. (2016). Working Capital Management: Evidence from Norway. International Journal of Managerial Finance, 12(3), 295-313. https://doi.org/10.1108/IJMF-01-2016-0012

Low, M. P. (2016). Corporate Social Responsibility and the Evolution of Internal Corporate Social Responsibility in 21 st Century. Asian Journal of Social Sciences and Management Studies, 3(1), 56-74. https://doi.org/10.20448/journal.500/2016.3.1/500.1.56.74

McWilliams, A., Siegel, D. S., \& Wright, P. M. (2006). Corporate Social Responsibility: Strategic Implications. Journal of Management Studies, 43(1), 1-18. https://doi.org/10.1111/j.1467-6486.2006.00580.x

Miralles-Quirós, J. L., Miralles-Quirós, M. D. M., \& Valente Gonçalves, L. M. (2019). The Profitability of Moving Average Rules: Smaller Is Better in the Brazilian Stock Market. Emerging Markets Finance and Trade, 55(1), 150-167. https://doi.org/10.3390/su11051404

Mzembe, A. N., \& Meaton, J. (2014). Driving Corporate Social Responsibility in the Malawian Mining Industry: a Stakeholder Perspective. Corporate Social Responsibility and Environmental Management, 21(4), 189-201. https://doi.org/10.1002/csr.1319 
Prado-Lorenzo, J. M., Gallego-Alvarez, I., \& Garcia-Sanchez, I. M. (2009). Stakeholder Engagement and Corporate Social Responsibility Reporting: the Ownership Structure effect. Corporate Social Responsibility and Environmental Management, 16(2), 94-107. https://doi.org/10.1002/csr.189

PricewaterhouseCoopers (PwC). (2020). 23 $3^{\text {rd }}$ Annual Global CEO Survey. Retrieved on February 15, 2020, from https://www.pwc.com/gx/en/ceo-survey/2020/reports/pwc23rd-global-ceo-survey.pdf

Saeidi, S. P., Sofian, S., Saeidi, P., Saeidi, S. P., \& Saeidi, S. A. (2015). How Does Corporate Social Responsibility Contribute to Firm Financial Performance? The Mediating Role of Competitive Advantage, Reputation, and Customer Satisfaction. Journal of Business Research, 68(2), 341-350. https://doi.org/10.1016/j.jbusres.2014.06.024

Santos, E. A., Soares, S., Sallaberry, J. D., \& Gonzaga, C. A. M. (2019) Influência da Responsabilidade Social Corporativa no Engajamento do Funcionário Mediado pela Identificação Organizacional. Anais do Congresso da Associação de Programas de PósGraduação em Ciências Contábeis, São Paulo, SP, Brasil, 13. Recuperado em 15 de Dezembro, 2019, de http://anpcont.org.br/pdf/2019_CCG319.pdf

Servaes, H., \& Tamayo, A. (2013). The Impact of Corporate Social Responsibility on Firm Value: The Role of Customer Awareness. Management Science, 59(5), 1045-1061. https://doi.org/10.1287/mnsc.1120.1630

Sidhoum, A. A., \& Serra, T. (2018). Corporate Sustainable Development. Revisiting the Relationship Between Corporate Social Responsibility Dimensions. Sustainable Development, 26(4), 365-378. https://doi.org/10.1002/sd.1711

Teixeira, E. A., Nossa, V., \& Funchal, B. (2011). O Índice de Sustentabilidade Empresarial (ISE) e os Impactos no Endividamento e na Percepção de Risco. Revista Contabilidade \& Finanças, 22(55), 29-44. https://doi.org/10.1590/S1519-70772011000100003

World Economic Forum. The Global Risks Report 2020. 15 th edition. Retrieved on February 15, 2020, from http://www3.weforum.org/docs/WEF_Global_Risk_Report 2020.pdf

Titman, S. (1984). The Effect of Capital Structure on a Firm's Liquidation Decision. Journal of Financial Economics, 13(1), 137-151. https://doi.org/10.1016/0304-405X(84)90035-7

Titman, S., \& Wessels, R. (1988). The Determinants of Capital Structure Choice. The Journal of finance, 43(1), 1-19. https://doi.org/10.1111/j.1540-6261.1988.tb02585.x

Rajan, R. G., \& Zingales, L. (1995). What Do We Know About Capital Structure? Some Evidence from International Data. The Journal of Finance, 50(5), 1421-1460. https://doi.org/10.1111/j.1540-6261.1995.tb05184.x

Refinitiv. (2019). Environmental, Social and Governance (ESG) Scores from Refinitiv. $\begin{array}{lllll}\text { Retrieved on } & \text { December } & 18, & \text { from }\end{array}$ https://www.refinitiv.com/content/dam/marketing/en_us/documents/methodology/esgscores-methodology.pdf

Roodman, D. (2009). How to do Xtabond2: An Introduction to Difference and System GMM in Stata. The Stata Journal, 9(1), 86-136. https://doi.org/10.1177/1536867X0900900106

Villarón-Peramato, Ó., Martínez-Ferrero, J., \& García-Sánchez, I. M. (2018). CSR as Entrenchment Strategy and Capital Structure: Corporate Governance and Investor Protection as Complementary and Substitutive Factors. Review of Managerial Science, 12(1), 27-64. https://doi.org/10.1007/s11846-016-0212-1

Wintoki, M. B., Linck, J. S., \& Netter, J. M. (2012). Endogeneity and the Dynamics of Internal Corporate Governance. Journal of Financial Economics, 105(3), 581-606. https://doi.org/10.1016/j.jfineco.2012.03.005

Wu, M. L. (2006). Corporate Social Performance, Corporate Financial Performance, and Firm Size: A Meta-Analysis. Journal of American Academy of Business, 8(1), 163-171. 


\section{CONGRESSO 11 a 15 de Dezembro A 2020 - FOZ DO IGUAÇU - PR}

Xiao, C., Wang, Q., Van Der Vaart, T., \& Van Donk, D. P. (2018). When Does Corporate Sustainability Performance Pay Off? The Impact of Country-Level Sustainability Performance. Ecological Economics, 146, 325-333. https://doi.org/10.1016/j.ecolecon.2017.11.025

Xu, S., Liu, D., \& Huang, J. (2015). Corporate Social Responsibility, the Cost of Equity Capital and Ownership Structure: An Analysis of Chinese Listed Firms. Australian Journal of Management, 40(2), 245-276. https://doi.org/10.1177/0312896213517894

Yang, S., He, F., Zhu, Q., \& Li, S. (2018). How Does Corporate Social Responsibility Change Capital Structure?. Asia-Pacific Journal of Accounting \& Economics, 25(3-4), 352-387. https://doi.org/10.1080/16081625.2017.1354710 